To this amount, however, must be added the portions of the Cape Breton and Inverness Coal Fields lying under the sea, which, supposing the seams can be worked a distance of five miles beyond high-water mark, will make the total area of the Nova Scotia Coal Fields 859 instead of 18,000 square miles.

The production in 1874 has also been greatly overstated in Dr. Si emens' Table, as I find by reference to the Government Inspector's Report for the year 1876 , that the production in 1874 was only 749,127 tons.

R. B.

Dr. Siemens informs us that the difference referred to by our correspondent chiefly arises from the fact that in American re. ports Nova Scotia is made to include the maritime province of New Brunswick as well as Cape Breton Island, both of which contain large areas of coal-fields, although those fields are as yet very imperfectly developed. The figures given in the address were taken from Macfarlane's very elaborate work on the "CoalRegions of America." Witl reference to the coal production, this should be for the year 1873 , and is also given on the anthority of Macfarlane, who quotes from the Report of the Department of Mines. -ED.]

\section{Greenwich as a Meteorological Observatory}

A CAREFUL examination of the interesting communication by Mr. Alexander Buchan to the Scottish Meteorological Society, on "The Temperature of the British Islands," based on observan tions for the thitteen years ending 1869 , fails to support his conclusion (NATURE, vol. XY., p. 450) that the proximity of London does not appreciably influence the temperature as recorded at the Royal Observatory, and that the temperature of Greenwich. during recent years has not been in excess of that of surrounding districts. The evidence is quite the reverse. Exiracting the figures, given by $\mathrm{Mr}$. Buchan in the paper referred to, for all the stations within a radius of sixty miles of the metropolis, sixteen in number besides Greenwich, it appears that their mean is $50^{\circ} \cdot \mathrm{x}$, that of Greenwich being $50^{\circ} \cdot 6$. Allowing for elevation, the values are respectively $50^{\circ} 68$ and $51^{\circ}{ }^{\circ} 3$. Omitting, how ever, several stations such as Camden Town, which, forming part of London, is clearly inadmissible for the comparison, and Maidstone and Canterbury, where observations were made on two years only of the thirteen, the temperature of the ten remaining stations is $50^{\circ} 59$. Thus, according to data furnished by Mr. Buchan himself, Greenwich is warmer than the south. east of England generally by more than half a degree $\left(0^{\circ} \cdot 54\right)$. It may be added that, from the same data, the temperature of the district under consideration north of the Thames is $50^{\circ} .5$, and south of the river $50^{\circ} .8$.

H. S. EATON

\section{Centralisation of Spectroscopy}

IN his letter (NATURE, vol, xv. p. 449) Prof. Smyth makes a statement respecting the new "half-prism" spectroscope which I cannot help thinking must be founded on a misapprehension of the principle involved. This will, I trust, be made clear when my paper is published in the forthcoming number of the Procediturs of the Royal Society; but meanwhile, as Prof. Smyth appears distnclined to wait for a full explanation of the instrument, I shall be most happy to answer his objections when he informs me what particular "laws of Sir Isaac Newton and nature" are in opposition to the principle of this spectroscope.

Against Prof. Smyth's confident assertion that all definition is lost in this instrument, which he has never seen and of which he can only know by hearsay, I have only to set the statement that a small experimental spectroscope on the new plan, with two " half-prisms," is, as a matter of fact, decidedly superior in defin nition, as well as in brightness of spectrum, to the large Creenwich spectroscope, with ten large compound" prisms, of which the excellence is sufficiently attested by the accordance of the results obtained for the sun's rotation by its means. This statement is based on a careful comparison of the sodium lines, and also of the $b$ group in the solar spectrum, as seen with the two instruments, $b_{3}$ and $b_{4}$ with the finer lines in their neighbourhood being shown with remarkable distinctness in the new form of spectroscope, small though it is. In this assertion, I think, I shall be fully borne out by several astronomers to whom I have shown the action of the new spectroscope.

Though I am not in any way concerned with Prof. Smyth's argument in the earlier part of his letter, I may mention for his information that "during the last twenty years" only two spectroscopes have been made for Greenwich Observatory (one of these having only a single prism of small dispersion), and that our second or powerful spectroscope was only made thre years ago; whilst the Edinburgh observatory has, for the past four years, possessed three spectroscopes which are almost precisely identical with those used with such effect by Dr. Huggins.

Royal Observatory, Greenwich, March 27 W. H. M. CHRISTIE

\section{Morphology of "Selaginella"}

BEFORE instituting a comparison it is generally prudent to ascertain that the things to be compared are comparable. I am

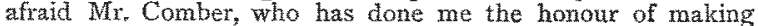
some remarks on what $T$ have said in the pages of NATuRE on the primordial type of flowers, has neglected this precaution. If I understand him rightly, he suggests that the "spike" of Selaginella is the homologne of the spike of Carex pulicaris. He compares, then, the scales bearing macrosporangia of the former with the lower glumes bearing each an ovary of the latter.

Now in the first place, if he had. studied the matter a little more (if he will allow me to say so), he would have seen that the ovule, and not the ovary, is the equivalent of the macrosporangium, and that the embryo sac, and not the ovule, is the equivalent of a macrospore. This leaves the ovary unaccounted for, and the homology hopelessly breaks down on that point.

But this is not all. Mr. Comber has omitted all notice of the singular structure, the perigynium, and also of the equally singular structure, the "seta," which it contains along with the ovary, and which happens to be particularly well represented in Carex. puthicaris. If he will take the trouble to look at a short paper which I have published in the Youtrnat of the Linnean Society (Botany) vol, xiv., pp. $154-156$, pl. xii., he will find that I have carefully discussed the morphology of the female fower of this very plant. I think I have suceeded in showing that far from being a simple racemose inflorescence it is a compound raceme or panicle reduced in a very peculiar manner. I am afraid, therefore, that Mr. Comber has been led away by resemblances of a very superficial character, and that the fact Selcoinello has a "spike" and that Carex has a "spike," is a point of contact between the two about as significant as the existence of a river in both Macedon and Monmouth.

In fact, far from being plants of a primitive type, the Cyperacee are generally regarded as reduced representatives of plants of much more fully developed character, the exact nature and relationship of which we have no materials for at present estimating. W. T. ThISELTON DYER

\section{Tungstate of Soda}

Wxit regard to your note (NATURz, vol. xy. p. 460) upon muslin rendered uninflammable by tungstate of soda, will you allow me to say that when properly prepared the muslin is fairly uninflammable. I say uninflammable-not freproof. There can be no doubt from experiments made in Prof. Gladstone's laboratory that mualin prepared with a sufficient quantity of the salt will not catch fire by ordinary means, but no one conld reasonably expect it to stand an auto a $f e$ such as that to which I saw Dr. Wright subject his dummy, and fortunately not his assistant, last Saturday fortnight.
MATrHeW W. WILLIAMS

$$
\text { Chemical Laboratory, Royal Institution }
$$

\section{Traquair's Monograph on British Carboniferous Ganoids}

WILL you kindly permit me through the medium of your journal, to correct and apologise for a very awkward blunder which occurs in the first part of my monograph on British carboniferous ganoids, recently published by the Palrontographical Society? In the introduction I have advocated the retention of the Dipnot as a distinct order of fishes, but at page $4 \mathrm{I}$, in a manner unaccountable to myself, for I certainly did not mean it, I have included them as a sub-order of the Ganoidei. That this "slip of the pen" was not detected in the revision of the proofs must have been due to an amount of carelessness of which I am justly ashamed.

Edinburgh, April 2 